\title{
Frightening conflictual identities and reassuring affective ties in our contemporary conspiracy narratives
}

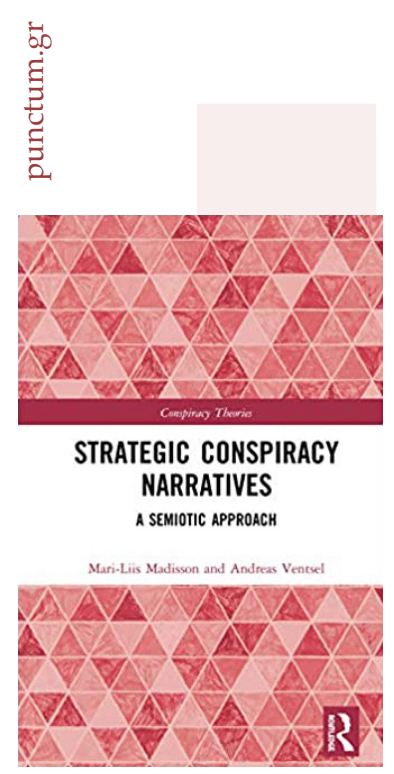

BY: Anna Maria Lorusso

Mari-Liis Madisson and Andreas Ventsel

Strategic Conspiracy Narratives. A Semiotic Approach

London, Routledge, $2021 £ 96.00$ (Hardback, ISBN 9780367030988), £29.59 (eBook, ISBN 9780429020384), 144 pp.

ARTICLE INFO:

\begin{tabular}{l}
\hline Volume: 07 \\
\hline Issue: 01 \\
\hline Summer 2021 \\
\hline ISSN: $2459-2943$ \\
\hline DOI: 10.18680/hss.2021.0011 \\
\hline Pages: 165-169 \\
\hline By: Anna Maria Lorusso \\
\hline Lic.: CC BY-NC-ND 4.0 \\
\hline
\end{tabular}

$\mathrm{M}$ ari-Liis Madisson and Andreas Ventsel's book deals with conspiracies in an original, systematic, and semiotic way. I highlight the word 'semiotic' because there is not much semiotic work on this topic (except for a research group coordinated by Massimo Leone at the University of Turin) despite its relevance. And yet, the semiotic take on conspiracies has an impressive forbear: Umberto Eco, to whom Madisson and Ventsel make ample reference. Eco has dealt with this topic extensively, both in non-fiction (first and foremost in The Limits of Interpretation, 1990) and fiction (all his novelistic plots, from Foucault's Pendulum to Numero Zero, are centered on the organization or unraveling of conspiracies).

The book is divided into two parts. The first one is dedicated to building the theoretical framework, whereas the second is to the semiotic analysis of Soros-themed conspiracy narratives. The theoretical part mainly focuses on the category of conflict (I.1) and identity (I.2), against which the narrative specificities of the conspiracy theories are defined and articulated.

The question of identity is central from the first chapter, and the entire conflictual dimension is appropriately viewed 
in these terms. Conspiracy narratives construct conflictuality, or rather, presuppose an existing conflictuality, defining identities in a polemical relationship that clearly divides the world between us vs. them, good vs. evil. In doing so, they simplify reality and are 'convenient,' as they help us put things in order. Madisson and Ventsel make this clear (12):

The identity of a semiotic unit (protagonist, antagonists, event, etc.) is not characterized by any authentic or primordial properties but rather defined through constantly developing processes of meaning-making, transformed in interplay with an altering socio-cultural context (Campbell 2008: 410). The processes of identity creation are not predetermined by certain essential (material or social) factors but suggest the making of semiotic choices, as well as a degree of contingency and unpredictability. The cultural semiotic approach sees the processes of identity creation as an integral part of communication and follows an antiessentialist perspective that treats identities as a matrix of difference. (Madisson 2016b: 22)

Throughout this process of the social construction of identities, Madisson and Ventsel need to keep in mind Lotman's lesson. As we know, he was particularly insistent on the identity mechanism through the category of the border, which finds the definition of the ego's perimeter in the demarcation of the other's space. We construct a non-ego, or an Other, precisely to establish our identity space, reinforcing it through a precise perimeter.

This construction of identity in conspiracy narratives assumes three functions:

1. Generating effects of inclusion/exclusion through a straightforward and Manichaean narrative;

2. Mobilising reactions: identity narratives do not just want to provide a world view, but to solicit pragmatic responses;

3. Confirming already existing social ties through the repetition and amplification of shared emotional elements.

In the second part, the authors find these characteristics in the anti-Soros conspiracy narratives. According to these, Soros is "the 'umbrella enemy,' the puppet master, allegedly pulling the strings of the biased mainstream media, the corrupt educational system, the European Union that undermines traditional values and nation-states, and the non-profit associations, etc., that advocate all possible kinds of minorities"' (58).

The authors identify three strategic areas in which the 'legend' of Soros circulates most, always catalyzing the entirety of the case's negativity, fishing through the collective memory for fears, narrative frames, and keywords, subsequently used al- 
most obsessively. First are the political narratives whose primary purpose is to form a political agenda. Then come strategic narratives, which offer an alternative vision of the world that, in turn, shapes institutions and educational systems. And finally, we have the marketing discourses that generally serve to capture attention and as infotainment. Anti-Soros conspiracy narratives work as a system and, at the same time, cut across all three of these areas. They advance a real war scenario at a political level; reinforce the nationalist worldviews of the different countries that espouse them (and I highlight the variety of countries, to underline how these rhetorical strategies adapt to and function in the most diverse contexts), and exploit anti-Semitic narratives. Simultaneously, at a marketing level, they fuel a series of anti-brand positions that target Soros as a man linked to large multinationals.

In the final chapter, the analysis concerns mainly the transmedial narratives of some Estonian radical right-wing sites. Here, Madisson and Ventsel focus on the use of the emotional dimension of conspiracy narratives - narratives made up not only of verbal language but also, and increasingly so, of visual and video elements.

This is the book's broad outline. However, I think it is essential to highlight its methodological and heuristic merits, which are many. First of all, the use of Umberto Eco's categories of model author and model reader (but above all, model author). Madisson and Ventsel very appropriately claim their usefulness for this type of conspiratorial narrative that we cannot trace to some defined empirical authorship. As they clearly state, "the question of attributing intentionality is one of the most complex problems in studying strategic communication on social media. From the perspective of our model, however, this is not a question of primary importance" (62). Still, it is not just a question of the specificity posed by social media and transmedia narratives. The fact is - and I am sure Madisson and Ventsel would agree - that conspiracy narratives present a widespread enunciative responsibility, whereby there is not only one enunciator responsible but a set of subjects which, in different ways and different discursive spaces, relaunch, perhaps with variations, the same conspiratorial core. Madisson and Ventsel do not consider enunciative categories but highlight this problem and rightly find in the category of Model Author a valuable tool to define a common and characterizing core. This, however, is determined textually, not empirically, through the set of texts that contribute to a conspiratorial narrative.

Madisson and Ventsel then recall Eco's hermetic semiosis, as defined in The Limits of Interpretation (1990). For the authors, the salient points are the following two. First, the tendency to see signs wherever one wants to see them and thus constructing interpretative chains with very weak logical links but apparent similarity links. Secondly, the tendency to see occult secrets at the heart of reality and share them within communities that become even more close-knit based on this esoteric knowledge. 
There is, in my opinion, another point of tacit consonance between Madisson and Ventsel's book and Eco's theories, and it concerns the symbolic dimension, crucial (according to the authors) in conspiracy narratives. In the first part of the book, our authors use the idea of the symbol as a semiotic function that, on the one hand, maintains persistence and recognisability over time and, on the other, transforms itself according to contexts. In this sense, for Madisson and Ventsel, symbols play a fundamental role as functions of the collective cultural memory. Conceiving symbols in transformation and their mnemonic function is, in my opinion, in harmony with Umberto Eco's preference, in Semiotics and Philosophy of Language (1980), for the expression 'symbolic mode' to 'symbol' to highlight that symbols are not particular types of signs but a special type of semantic-pragmatic attitude, a particular type of interpretation. More precisely, it is a matter of identifying links between expressions already defined (i.e., already assigned to a specified content) and a nebula of content that the encyclopedia offers for association with that expression - a nebula authorizing a non-exhaustible range of interpretations. For Eco, therefore, the symbolic mode adapts to context while having an expressive recognisability. For this reason, it represents a particularly relevant resource for conspiratorial narratives, which widely exploit the openness of interpretations.

On this, however, another relevant aspect of the volume should be highlighted: Madisson and Ventsel, in their theoretical framework, highlight how, in the narrative logic of conspiracy, there is a double register, so to speak, that is both discrete and continuous. We find a discrete logic in the oppositional schematizations typical of conspiracies. Manichaeism presupposes clear demarcation boundaries; the war scenarios often exploited, constructed and reinforced are based on a clear clash of fronts. This, however, does not exclude a logic of the continuous: confusing, based (in an Echian sense) on analogies and similarities, which goes hand in hand with the crucial role of symbols, which, as we have just said, function as open-ended functors.

This is how, in a discursive landscape characterized by large swathes of 'information fog' (as the authors put it), conspiracy narratives can circulate freely, exploiting the fog, while making a show of offering their audience a key with which to understand the world (and dispel that fog).

Finally, one last aspect I would like to note as particularly interesting in the volume is its attention to the phatic dimension of discourse. "In such communication, the meaning of words is nearly irrelevant. The expressions are rather used in the function of confirming social ties, which can be expressed in, e.g., establishing an intimate atmosphere conducive to social connection. The information exchanged in the course of phatic communication is indexical rather than referential; it reflects the (in)acceptance of the communication partner and attributes a certain status to them" (40). 
I believe that this aspect of conspiracy narratives (and perhaps much of current infodemics) has not been sufficiently emphasized so far. Beyond and even before any worldview, I believe that conspiracies aim to create social bonds, and for this reason, they have no problem with taking even contradictory positions. There is no logical contradiction that is relevant. What is relevant is maintaining the flow of communication and affection, thus a continued compacting of one's community and its eventual expansion.

As Madisson and Ventsel point out in their conclusions, it would be interesting to test this theoretical framework on an extended corpus of conspiracy theories; in fact, the book only deals with the Soros case (admittedly, a very relevant case). To see, for example, whether there are differences in semiotic functioning between countries with very different political histories (do conspiracy theories work in the United States as they do in Argentina or the former Soviet Union?); whether the cultural histories of different countries have 'pre-formed' different recurring scripts or whether the contemporary multidirectional memory that Michael Rothberg talks about has also produced multidirectional conspiracies, which with slight variations circulate in the same way; how conspiracy theories change or adapt when non-human subjects enter the scene (a virus, a natural catastrophe).

In short: semiotics still has a lot of valuable work to do! This volume demonstrates convincingly that Umberto Eco and Juri Lotman have left us many useful heuristic tools to analyze conspiratorial 'pathologies.' Perhaps the integration with some socio-semiotic reflections (I am thinking of Landowski's studies) and enunciative ones could further enrich the heuristics of our view.

\section{AUTHOR}

Anna Maria Lorusso Associate Professor of Philosophy and Theory of Language, University of Bologna, Italy. 